\title{
LEV TOLSTOY E PIOTR KROPOTKIN COMO CRÍTICOS DA EDUCAÇÃO GEOGRÁFICA
}

\section{LEV TOLSTOY AND PIOTR KROPOTKIN LIKE CRITICS OF GEOGRAPHIC EDUCATION}

\author{
Amir El Hakim de Paula \\ Professor Assistente Doutor da UNESP-Ourinhos \\ e-mail:amir@ourinhos.unesp.br
}

\begin{abstract}
RESUMO
Esse artigo tem como objetivo discutir as críticas à Geografia escolar realizadas por dois importantes teóricos russos: Lev Tolstoy e PiotrKropotkin. Kropotkin, reconhecido humanista e anarquista, procurou apontar as deficiências que a Geografia tinha no que tange a sua aplicação na escola básica, seja por seu aspecto mnemônico ou por ressaltar nacionalismos e a submissão das chamadas "raças inferiores". No caso de Tolstoy, apontaremos a sua experiência no projeto escolar realizado em sua cidade natal, bem como, a crítica que o grande escritor russo realizou contra a Geografia encontrada nos manuais escolares da primeira metade do século XIX.
\end{abstract}

Palavras-Chave: Anarquismo; Educação; Geografia; Crítica; Século XIX

\begin{abstract}
This article aim discuss the critical to school Geography performed by two important theoretical Russians: Lev Tolstoy and Piotr Kropotkin. Kropotkin, anarchist and humanist recognized sought to point out the deficiencies that geography had in regard to its application in elementary school, for his mnemonic or emphasize nationalism and submission to "inferior races". Where Tolstoy, we consider their experience in school project held in his hometown as well as the criticism that the great Russian writer will held Geography textbooks found in the first half of the nineteenth century.

Keywords: Anarchism; Education; Geography; Critic; 19 Century
\end{abstract}




\section{Introdução}

PiotrKropotkin e Lev Tolstoy, reconhecidos mundialmente pelos trabalhos desenvolvidos, ainda são praticamente desconhecidos no que tange à educação e principalmente a crítica à Geografia escolar.

Nesse artigo desenvolvemos uma análise, ainda que inicial, acerca de como ambos criticam as aulas de Geografia nas escolas do século XIX, momento marcado pela própria estruturação da Geografia como uma ciência.

Interessante anotar que, muito embora sejam poucos comentados, PiotrKropotkin e Lev Tolstoy tinham grandes preocupações sobre como as aulas eram ministradas às crianças, levando-se em consideração que nessa época, era comum o uso da violência enquanto prática pedagógica.

Ambos sendo participantes de uma visão libertária de educação questionariam o caráter descritivo da Geografia, vista então pelos alunos como uma disciplina enfadonha e de pouquíssimo interesse.

Embora a preocupação de Tolstoy, como veremos, fosse além de uma crítica à Geografia escolar, sua experiência educacional em Yasnaia Poliana é de extrema importância, pois ajuda-nos compreender a aplicação de técnicas educacionais completamente divergentes daquelas mais comumente aceitas.

No caso de Kropotkin, é extensa a sua influência na educação enquanto anarquista (participante do Encontro Internacional de 1886) e geógrafo, tendo análises que versam desde o apoio mútuo até o surgimento da orografia euroasiática, inclusive sendo co-autor do capítulo da Rússia na obra de EliseéReclus.

Esperamos que esse artigo possa ensejar novas descobertas acerca da educação e da Geografia, demonstrando a importância de dois pensadores russos de grande expressividade no século XIX, mas que se mostram atuais ainda nesse século que apenas se inicia.

\section{Lev Tolstoy e a escola de Yasnaia Poliana: Por uma Geografia libertária}

Lev Tolstoy (1828-1910) é mundialmente conhecido pela sua extensa obra literária, inclusive sendo traduzida em mais de 40 idiomas. Em que pese o largo conhecimento de seus trabalhos, poucos são os leitores e pesquisadores que tiveram contato com as pesquisas que o escritor russo empreendeu na área de educação. 
O principal trabalho desenvolvido por Tolstoy nessa temática surge quando o escritor russo torna-se diretor de um colégio para camponesespobres na região de Tula, a Rússia. Em sua cidade natal, Yasnáia Poliana, Tolstoy procurou aplicar uma forma de organização educacionalanti-autoritária, no qual os alunos teriam grande participação no desenvolvimento interno da escola.

A experiência libertária educacional ocorreu logo após Tolstoy ter chegado da Europa Ocidental e, entre outras coisas, tomado contato com a obra de Proudhon, conhecendo o economista anarquista pessoalmente. ${ }^{1}$

Desse encontro, Tolstoy conheceu as análises do pensador francês acerca da educação numa sociedade de classes, principalmente a proposta de Proudhon sobre a importância do ensino politécnico.

Para Proudhon, os alunos mais pobres deveriam receber a mesma instrução daqueles das famílias mais abastadas. Ou seja, necessitariam tanto um ensino voltado ao trabalho, o que ele chamou de politécnico como daquele ligado a uma formação científica, como forma de não se perpetuar uma separação entre os alunos abastados (que recebiam uma formação clássica, e por isso capazes de dirigir a sociedade)e os pobres (que recebendo apenas uma educação para o trabalho não seriam capazes de construírem novas formas de emancipação humana). ${ }^{2}$

Pensando nessas questões, Tolstoy volta para a Rússia e vai dirigir uma das primeiras experiências libertárias de ensino.

\section{A escola de Yasnaia Poliana: Prática de educação libertária.}

Ainda que nascida de uma enorme vontade de Tolstoy de aplicar os conhecimentos adquiridos em sua primeira passagem pela Europa Ocidental (soberbamente aqueles surgidos após o seu encontro com Proudhon), a escola que o escritor russo dirigirá em sua cidade natal ainda terá forte influência da Igreja Ortodoxa, estando presente disciplinas sobre ensino religioso e história sagrada.

Além dessas matérias, a escola tinha Leitura mecânica e progressiva, Escrita,

\footnotetext{
1Interessante anotar que a influência de Proudhon foi imensa. Só para constar, uma das suas principais obras do escritor russo, Guerra e Paz, teve o título tiradodo livro "La Guerre et laPaix" de Pierre J. Proudhon.
}

2Mais detalhes acerca da visão proudhoniana, ver: Codelo (2007)

Geo UERJ. Rio de Janeiro - Ano 16, no . 25, v.2, $2^{\circ}$ semestre de 2014, pp.231-249

ISSN: 1415-7543 E-ISSN: 1981-9021

http://www.e-publicacoes.uerj.br/index.php/geouerj 
Caligrafia, Gramática, História da Rússia, Desenho, Desenho linear, Canto, Matemática e Conversações sobre ciências naturais.

Em que pese a semelhança do currículo comum aos alunos das escolas russas de então, conforme vamos aprofundando o estudo sobre essa experiência, percebemos que pouca coisa do ensino tradicional era trabalhado na escola administrada por Tolstoy.

Um dos componentes formadores desse ensino era a liberdade. E a liberdade era a todo momento incentivada, mesmo quando ela, supostamente, poderia trazer embaraços ao professor.

Isso poderia ocorrer se o aluno não se interessasse em fazer as lições. Ou seja, ele teria a liberdade de escolher o que fazer e quando fazer, e se eventualmente, não quisesse fazer nada, a ele era dado a liberdade dessa escolha. Vejamos abaixo um extenso relato de Tolstoy (1978, p.16) sobre isso:

Ninguno lleva nada consigo; ni libro ni cuaderno; nunca se les impone deberes que cumplir en casa. Y no sólo el niño no lleva nada en las manos, sino que tampoco lleva nada en la cabeza. Nada de lección; no está obligado a preocuparse hoy de lo que hizo ayer. No se tortura el entendimiento para la lección que va a seguir. No lleva más que a sí mismo, su naturaleza impresionable, y la certeza de que la escuela será hoy tan alegre como ayer. No piensa en la clase hasta el momento en que ésta comienza.

Tolstoy aponta nesse parágrafo que o ensino não deveria estar ligado a qualquer tipo de constrangimento. Ninguém aprenderia algo por meio do medo. Exigir que algum aluno fizesse a tarefa de casa necessariamente não estimularia a formação de um aluno mais dinâmico e muito menos, autônomo.

Para Tolstoy, o aprendizado deve estar ligado umbilicalmente à alegria e que não se aprende nada se o motivador principal não seja a curiosidade.

Um fato corriqueiro em nossas salas de aula, o mapeamento dos alunos, era inexistente na escola administrada por Tolstoy. Essa estratégia dos professores serve basicamente para determinar a posição que o aluno terá na sala de aula ao se sentar, já que, supostamente, isso ajudaria o professor a controlar os alunos mais indisciplinados.

$\mathrm{Na}$ escola tolstoyana essa prerrogativa do professor era desnecessária visto que os alunos sentavam no local que mais lhes aprazia, independente ainda de se ter ali uma cadeira ou não. Como afirma Tolstoy (1978, p.18): "Se sientam donde les parece bien: 
sobre los bancos, las mesas, en el poyo de la ventana, en entarimado, en el sillón.”

Ao se permitir ao alunado a escolha do localna sala de aula que se disporia, e que essa posição poderia ser modificada conforme o seu desejo, os professores e gestores dividiam com os discentes a responsabilidade da organização da escola e logo a indisciplina não seria apenas objeto de apreciação do professor.

E com isso quaisquer atos que pudessem ser encarados como perturbadores do funcionamento da escola deveriam ser discutidos entre os alunos, os mestres e os administradores, visto que o corpo diretivo da escola seria composto pelo conjunto formado por discentes, docentes e gestores ${ }^{3}$.

Interessante anotar também que houve casos de roubos na escola, na qual as soluções sempre partiam dos alunos, muito embora essa liberdade não significasse sempre a busca por uma solução menos traumática.

Quando isso ocorria, ou seja, quando os alunos tomavam uma decisão quecontradizia uma prática mais libertária, Tolstoy demonstrava desânimo e procurava entender por que os alunos tinham assim tomado essa decisão mais autoritária.

Como as aulas eram ministradas baseando-se sempre na formação de um ambiente solidário e livre, as relações entre o professor e o aluno, fora da escola, demonstravam a força dos aspectos presentes no ambiente escolar.

DizTolstoy (1978, p.35):

Fuera de la escuela, en plena libertad, al aire libre, se establecen entre losalumnos y el maestro relaciones nuevas, en las que reinan la mayor franqueza de conducta, la confianza más grande. Las mismas relacionesque nos parece deben ser como el ideal que debe tender la escuela.

Partindo do convívio entre alunos e professores nos quais a hierarquia não estivesse presente, a escola autônoma administrada por Tolstoy procurava formar cidadãos conscientes de sua posição social e, principalmente, que as condições sociais vivenciadas eram frutos de uma sociedade baseada em explorados e exploradores.

Nesse sentido, na sala de aula procurava-se romper com uma relação tão presente até os dias de hoje no qual o professor supostamente possui o saber e cabe ao

\footnotetext{
${ }^{3}$ Foucault (2004, p.126) ao analisar a questão disciplinar nas escolas do século XVIII aponta, por meio de um educador da época, como eram organizadas as salas de aula: "Haverá em todas as salas de aula lugares determinados para todos os escolares de todas as classes, de maneira que todos os da mesma classe sejam colocados num mesmo lugar e sempre fixo. [...] Cada um dos alunos terá seu lugar marcado e nenhum o deixará nem trocará sem a ordem e o consentimento do inspetor das escolas."
}

Geo UERJ. Rio de Janeiro - Ano 16, nº. 25, v.2, $2^{\circ}$ semestre de 2014, pp.231-249

ISSN: 1415-7543 E-ISSN: 1981-9021

http://www.e-publicacoes.uerj.br/index.php/geouerj 
aluno adaptar-se ao tipo de aula ministrada.

Para Tolstoy (1978, p.52) o método docente era um componente essencial para uma melhor compreensão do tema apresentado. Para ele

[...] el maestro está siempre llevado involuntariamente a escoger el procedimiento de enseñanza más cómodo. Cuanto mascómodo es este procedimiento para el maestro, más incomodo es para los discípulos. Soloesbuenoaquel que satisface a losalumnos.

Nesse sentido, a dinâmica da apresentação dos conteúdos deve, levar em consideração, o grau de compreensão dos alunos, a sua aptidão para o tema e, principalmente, a escolha de meios e materiais para que o conteúdo seja transmitido ludicamente, proporcionando uma grande receptividade dos discentes.

Caso contrário, a aula se transforma em algo enfadonho, tanto para os alunos como para o professor, surge a indisciplina e com ela a necessidade de se tomar métodos coercitivos, trazendo ao ambiente da sala de aula o desgaste natural entre professor e alunos.

A prática docente, para Tolstoy, não pode estar dissociada de um aspecto de enorme importância na sala de aula: a convivência democrática entre docentes e discentes.

Sabe mais o professor que se preocupa em transmitir o conteúdo dialogicamente, demonstrando as várias hipóteses de trabalho que um tema específico possa ser encaminhado, negando-se a se assumir como a única "fonte" de saber.

A liberdade na escola e na sala de aula só é possível se o professor demonstrar que seu conhecimento, embora de extrema importância, nada significa se não conseguir atingir os principais interessados, e isso só é possível quando a proposta de trabalho envolver um diálogo constante entre a sua prática docente e os objetivos dos alunos em sala de aula.

Para Tolstoy (1978, p.57)

[...] sin esta libertad, sin este desorden exterior, que algunos encuentran tan extraños, tan imposibles, no sólo no habríamos encontrado cinco métodos de lecturas, sino que ni aun podríamos emplearlos, altérnalos, conforme a los deseos de los niños, y entonces no habríamos obtenido nunca los espléndidos resultados que hemos alcanzado en estos últimos tiempos en la 
lectura.

Ou seja, a prática docente, para Tolstoy, envolve idas e vindas; erros e acertos; a liberdade como um aspecto primordial na relação entre todos. A experiência da escola de Yasnaia Poliana oferece-nos uma outra forma de compreender o ensino; conhecê-la ajuda-nos a rever a nossa prática cotidiana e, quem sabe, construirmos uma educação mais humana, solidária e democrática.

Mas uma questão vem a nossa mente: a experiência educacional tolstoyana deve ser o nosso modelo de educação a partir de agora? Responde-nos o próprio escritor russo: "Cuantas veces les hemos oído formar el proyecto de introducir em sus escuelas tal sistema que, desconocido entre ellos, funciona a su visto emYasnaiaPoliana, pero no en modo alguno a título de regla despótica impuesto a todos." (TOLSTOY, 1978,p.58)

Muito embora a escola de Tolstoy forneça-nos subsídios para a construção de uma educação mais participativa, não cabe a nós (professores, alunos e gestores) seguir estritamente uma experiência ocorrida há mais de 150 anos e de um país tão diverso culturalmente do nosso.

Entretanto para pensarmos uma outra escola, onde a democracia interna seja realmente valorizada, no qual a participação de toda a comunidade seja efetiva, essas experiências são de extrema importância e ajudam-nos a compreender criticamente esse momento da educação brasileira.

\section{As análises de Tolstoy sobre a Geografia escolar}

Um dos momentos mais interessantes e importantes na obra educacional de Tolstoy ocorre quando ele inicia uma análise acerca das matérias ministradas na escola e de que forma elas eram compreendidas pelos alunos.

Como comentamos anteriormente, o currículo ministrado nessa escola experimental não era diferente dos outros colégios da região, quiça da Rússia Imperial. Entretanto, como a apresentação das aulas era um componente de grande relevância, visto se tratar de uma escola libertária, a crítica ao conteúdo era um assunto comum e mudanças na forma de entender a matéria era a todo momento trabalhado.

Dois capítulos do livro de Tolstoy sobre a escola experimental, para nós, são de grande valia, já que comentam de que forma os alunos recepcionavam o ensino de 
Geografia e quais as críticas que a ele faziam.

No capítulo VIII da parte II do livro, Tolstoy analisa o ensino da Geografia nacional, a ideia de nação e de governo.

Nessa discussão, apresenta a intenção de um professor em inculcar nos alunos os valores nacionais e a dificuldade que ele vai tendo conforme as perguntas dos discentes aparecem.

A primeira questão levantada é em qual país vivem e as respostas demonstram que, para alguns alunos, ser de algum país é tão vago quanto pertencer ao reino dos vertebrados.

Um deles aponta que seu país é a cidade onde mora (Yasnaia Poliana) e outro, mais genericamente, simplesmente responde : os campos!

Tolstoy vai percebendo o fato de serem crianças de 8 ou 9 anos muito pouco da ideia de nação está presente. Para grande parte desses alunos, a comunidade a que pertencem é o local de moradia/nascimento, visto que são, em sua maioria, filhos de camponeses.

Desta forma, pertencer a uma nação, ou ser russo, era algo ainda muito vago para as crianças. Elas se entendiam como pertencentes ao local e não ligavam-se às questões nacionais de um país tão vasto e com tantas nacionalidades como a Rússia imperial.

Outra questão que suscitou debate entre professor e alunos refere-se à questão do Poder e a separação entre as classes.

Quando o professor interroga os alunos sobre as classes sociais existentes na região em que vivem e quais as suas funções, os alunos respondem: “Los mujikslabran a tierra, los criados sirven a losbarines, losmercaderestrafican, los soldados se baten, lossamovarschikifabrican samovares, lospopesofician, losbarines no hacen nada.”(Tolstoy,1978, p.112)

Em que pese o professor tentar demonstrar a necessidade de leis, fronteiras, etc, fica claro que os alunos, por serem pequenos, não conseguiam captar corretamente as instruções.

Para Tolstoy, o professor ao tentar corroborar uma condição de existência (a presença de países, limites, poderes, etc) como algo naturalizado, acabou prestando um desserviço. 
Mais importante do que isso seria, segundo o escritor russo, propor aos alunos novas formas de entender a questão nacional, de Poder, para que eles pudessem compreender como a vida funciona no seu local de moradia, sem necessariamente, se preocuparem com as questões referentes a algo mais do que abstrato, tratando-se de crianças em processo de formação.

Comentando sobre a maneira do professor ministrar esses conteúdos, Tolstoy (1978, p.113-114) diz:

La lección se prolonga, poco más o menos, dos horas; el maestro está convencido de que los niños han retenido mucho de lo que se ha dicho, y siguen por el mismo camino las lecciones siguientes. Esto sin que a larga deje de reconocer la falsedad de este sistema y lo absolutamente absurdo de todo lo que hace.

Ainda que o professor ache que o conteúdo fora absorvido pelos alunos e que por isso as aulas devessem continuar nessa metodologia, Tolstoy apresenta que faltou ao docente apontar as várias situações que a discussão sobre nação propiciaria, principalmente no que tange à falsidade desse sistema.

Mais adiante, no Capítulo $\mathrm{X}$ da parte II,o autor procura demonstrar a necessidade de se ensinar Geografia, as várias tentativas de ensinar especificamentea Geografia física, a pouca compreensão dos alunos, e por fim, o desgosto das crianças pela forma que o tema é apresentado.

Na sala de aula no qual Tolstoy tentou ministrar Geografia, a maioria dos alunos era composta de filhos de camponeses (mujiks) com a idade de 10 anos.

Uma das questões que Tolstoy tentou trabalhar (sem muito sucesso, segundo ele próprio) era sobre o movimento de translação da Terra, e consequentemente, as estações do ano.

Essa discussão ocorreu também porque os alunos traziam a ideia de que a Terra não se movimentava, já que tal afirmação era corroborada pela Igreja Ortodoxa.

Tolstoy então se utiliza de um aspecto científico para refutar o pensamento religioso, ainda muito arraigado às famílias camponesas da região de Tula.

Mesmo com esse esforço de transmitir uma nova postura perante ao movimento aparente do sol, o escritor russo demonstrou certa insegurança, principalmente quando um aluno, segundo ele o mais cético, questionou como a Terra se movimentava, se as pessoas continuavam fixadas no mesmo lugar.

Geo UERJ. Rio de Janeiro - Ano 16, no . 25, v.2, $2^{\circ}$ semestre de 2014, pp.231-249

ISSN: 1415-7543 E-ISSN: 1981-9021

http://www.e-publicacoes.uerj.br/index.php/geouerj 
Fazendo uma autoavaliação da forma que o conteúdo era transmitido, o escritor russo conclui que a dificuldade de percepção e assimilação dos alunos, em relação aos conteúdos da Geografia física, devia-se também a uma naturalização das ideias geográficas pelo professor, que não tinha a preocupação de responder os "por quês" dos fenômenos. Diz sobre issoTolstoy (1978, p.120-121)

En la enseñanza de la Geografia, como de todas las demás materias, la falta más habitual, la más grosera, la más dañosa, es la demasiada precipitación. Nos hemos alegrado tanto de aprender que la Tierra es redonda y gira alredor del sol, que nos apresurarnos a transmitirlo lo más pronto posible al discípulo. Pero lo que es preciso no es saber que la Tierra es redonda es saber como se ha llegado a ello.

Na verdade o que Tolstoy questiona acerca da Geografia, especificamente, é a falta de dinamismo dela enquanto disciplina escolar em explicar os fenômenos desde o seu início, preocupando-se apenas em passar os conteúdos mnemônicamente, para que o aluno apenas saiba que tal fenômeno ocorre, sem necessariamente ter conhecimento sobre a sua origem e posterior processo.

Após “fracassar" na aula de Geografia física, Tolstoy (1978, p.121) passa à uma discussão da Geografia humana. E, para tanto, discute a presença de países e seus respectivos continentes. De novo, a questãocai nos "por quês":

En qué parte del mundo se encuentra Francia?(después de haber dicho un minuto antes que Inglaterra y Francia se encuentran em Europa), alguno exclamará que Francia está en África. La pregunta "por qué?" aparece em cada mirada apagada, en cada sonido de la voz, cuando se comienza la Geografia; y no hay respuesta a esta triste pregunta "por que"?

Ou seja, mais uma vez, só que agora em um tema específico da Geografia humana o aluno questiona a divisão dos países por continentes. Como as informações em mapas procuram, de alguma forma, reforçar essa divisão, fica a questão do "por que?" existem essas divisões continentais, e quiçá, nacionais, visto tal informação aparecer quase sempre na sala de aula com um dado natural.

Na verdade, para Tolstoy fica cada vez mais claro que o ensino de Geografia tem um componente mnemônico predominante. Mais importante do que estimular nos discentes o conhecimento dos lugares com suas particularidades, algo que incluísse, inclusive, os povos, com suas culturas, a relação do homem com a natureza, etc,a Geo UERJ. Rio de Janeiro - Ano 16, nº. 25, v.2, $2^{\circ}$ semestre de 2014, pp.231-249 
Geografia escolar aborda os temas fragmentados, restando ao aluno guardar nomenclaturas que, quase sempre, são esquecidas poucos dias depois de supostamente trabalhadas.

Para o escritor russo, os livros didáticos então existentes na Rússia acabavam sendo os principais veículos dessa Geografia escolar tradicional e caberia ao professor que ministra aulas em não adotá-los na escola.

Ao questionar esses livros, Tolstoy (1978, p.122) analisa qual deveria ser o papel desenvolvido pela Geografia:

La Geografia era unicamente lo que se aprendia de memoria. De todos los libros nuevos, Groubé, Biernodisk, ni uno era interesante.[...] el mejor modelo, a juicio mío, de lo que es preciso hacer para preparar lon niños al estudio de la Geografia, es decir, para despertar en ellos el gusto de la Geografia.

Ao contrário da Geografia encontrada nos livros didáticos, Tolstoy compreende que mais significativo para os alunos que aprendem a Geografia é assimilarem não os nomes, datas, nomenclaturas, etc, mas os sucessos e insucessos dos povos, suas culturas, os fenômenos físicos, dados que, de alguma forma, contribuíssem para a construção de uma Geografia mais dinâmica.

Não se trata, como ele mesmo demonstra, de desenhar os mapas para se fixar nomes de países e suas respectivas capitais. Qual o interesse em saber o que ocorre em Barcelona, se não conseguimos entender os problemas do nosso local de moradia? E, se o interesse aumenta pela Geografia quando abordamos temas mais voltados à nossa realidade, como trabalhá-los?

Vê-se que a Geografia tolstoyana, se podemos dizer desta forma, muito se diferenciava daquela encontrada nos livros didáticos e que causavam extremo desinteresse nos alunos.

Embora não sendo geógrafo de formação, Tolstoy, ao tentar trabalhar a matéria em sua escola, percebeu a quase que total separação entre a ciência geográfica e a realidade de alunos do ensino primário, ao ponto de propor que a disciplina fosse extinta dos meios escolares e subsistisse apenas na universidade.

A Geografia se quer ser uma disciplina interessante aos alunos das escolas primárias e secundárias, deveria abrir mão se seu formato mnemônico, abandonar imediatamente o discurso patriótico e

Geo UERJ. Rio de Janeiro - Ano 16, no. 25, v.2, $2^{\circ}$ semestre de 2014, pp.231-249

ISSN: 1415-7543 E-ISSN: 1981-9021

http://www.e-publicacoes.uerj.br/index.php/geouerj 
inspirar el deseo de saber como vive, ha vivido, se ha transformado y desenvuelto el género humano en los diferentes reinos, saber las leyes según las cuales la humanidad evoluciona eternamente; inspirar, por otra parte, el deseo de comprender las leyes de los fenómenos naturales en el mundo entero y la distribución del género humano sobre la superficie del globo (TOLSTOY, 1978, p.26)

Ao não conseguir despertar no aluno o interesse pela Geografia e, perceber também, que esses estudos eram demasiadamente estatísticos, no qual aprender se resumia a lembrança de dados, Tolstoy, já em meados do século XIX, muito antes do movimento de renovação da Geografia, tecia críticas sobre a sua composição no ambiente escolar.

Ao trazermos Tolstoy para essa discussão, procuramos demonstrar que, embora pouco conhecida, a obra educacional do escritor russo ajuda-nos também a refletir sobre a escola na atualidade, com todas as suas dificuldades de gestão, como também se o ensino de Geografia conseguiu, finalmente, se afastar da lógica dominante no período em que o grande escritor russo escrevia essas palavras.

\section{PiotrKropotkin: $O$ ensino libertário enquanto crítica da Geografia escolar}

PiotrKropotkin (1842-1921) foi um renomado pensador anarquista do século XIX, sendo inclusive referenciado como um dos principais articuladores de uma vertente do anarquismo com grande influência no Brasil no início do século XX: o anarco-comunismo.

Além de sua grande vultuosidade no pensamento libertário, Kropotkin é conhecido sobre as suas análises nos vários campos das ciências humanas e naturais: desde a geomorfologia, quando divergiu das contribuições humboldtianas acerca do surgimento da região orográfica asiática, passando pela biologia nas críticas à Thomas Huxley, quando contrapôs à chamada "luta pela sobrevivência" entre as espécies, o apoio mútuo, bem como nas análises sobre a espacialização da indústria.

Embora bastante conhecido em várias áreas científicas os seus trabalhos que envolvem uma discussão sobre o ensino de Geografia ainda estão escassamente divulgados, embora nos últimos anos professores universitários e/ou abnegados militantes anarquistas tem procurado uma maior divulgação de sua obra.

Nessa parte do artigo, procuraremos demonstrar de que forma Kropotkin, Geo UERJ. Rio de Janeiro - Ano 16, nº. 25, v.2, $2^{\circ}$ semestre de 2014, pp.231-249

ISSN: 1415-7543 E-ISSN: 1981-9021

http://www.e-publicacoes.uerj.br/index.php/geouerj 
participando de vários encontros da Royal GeographicalSociety (RGS) de Londres, inclusive debatendo com Halford John Mackinder ${ }^{4}$, discutiu e refutou o ensino de Geografia mnemônico, propondo, em contrapartida a essa metodologia escolar tradicional, uma didática que valorizasse o estudo das ciências naturais e o zelo pela cultura das chamadas "raças inferiores", entre outras coisas.

\section{A importância de PiotrKropotkin na construção do ensino de Geografia}

Muito embora Kropotkin ainda seja pouco conhecido na Geografia, sendo, inclusive, raramente citado nos artigos sobre ensino, no final do século XIX o príncipe anarquista era constantemente convidado para debater nas principais sociedades geográficas da Europa, seja por seus extensos trabalhos na Geografia física (quando recebeu medalha de ouro da sociedade geográfica russa, sendo inclusive alçado a coordenador dessa área na instituição) ou por gerar entre os participantes desses encontros, como afirma Vesentini (2008, p.17) “[...] um misto de benevolência e curiosidade: afinal ele era originário de uma aristocrática família russa[...]"

Ao defender os chamados "povos bárbaros" contra a invasão neocolonialista europeia, Kropotkin apresentava também a sua visão de Geografia escolar e por qual motivo essa disciplina tinha poucos adeptos na escola normal.

Diferente de Mackinder que defendia abertamente nos debates promovidos pela Sociedade Geográfica de Londres a utilização da Geografia como veículo de perpetuação de desigualdades entre os homens, o geógrafo russo era adepto de um ensino voltado a todas as classes sociais. (VESENTINI, 2008)

Ao propor um ensino universal, Kropotkin almejava uma ciência direcionada também à transformação social, propiciando, por meio dos estudos dos fenômenos naturais e humanos, a busca de uma sociedade mais justa e fraterna.

Embora, como afirma Vesentini (2008) essas proposições não surtissem o efeito desejável, ou seja, as análises classistas e eurocêntricas de Mackinder tiveram melhor efeito, não podemos deixar de destacar as inúmeras contribuições de Kropotkin para a Geografia, inclusive na área do ensino.

\footnotetext{
4Uma parte dessa discussão pode ser analisada no artigo Controvérsias geográficas: epistemologia e política de José Willian Vesentini, disponível na Revista franco brasileira de Geografia Confins, $n^{\circ} 2$, 2008.
}

Geo UERJ. Rio de Janeiro - Ano 16, nº. 25, v.2, $2^{\circ}$ semestre de 2014, pp.231-249

ISSN: 1415-7543 E-ISSN: 1981-9021

http://www.e-publicacoes.uerj.br/index.php/geouerj 
Se como vimos anteriormente, Tolstoy se utilizou de uma experimentação educacional em Yasnaia Poliana para levar a frente suas convicções libertárias, Kropotkin, mesmo que não organizando um sistema de ensino, propiciou inúmeras contribuições aos estabelecimentos escolares que, de alguma forma, se utilizavam de uma metodologia libertária.

Uma das experiência mais famosas na educação do século XX foram as Escolas Modernas, criadas em 1901 na Espanha, pelo pedagogo catalão Francisco Ferrer y Guardia e tinham como objetivo educar as classes trabalhadoras de uma maneira racionalista, secular e não coercitiva.

As aulas na Escola Moderna muito se diferenciavam dos estabelecimentos laicos e religiosos existentes, visto que as salas de aula eram mistas, a relação professor e alunos era pautada no diálogo e, para se ensinar ciências naturais e Geografia, o estudo do meio era a todo momento incentivado. Ou seja, enquanto na maior parte das escolas daquele período as salas de aula eram separadas por gênero, o professor era o único vetor do saber, sendo comum o uso da violência, nas Escolas Modernas se projetava um ensino mais humano e coerente com as premissas anarquistas.

Em uma carta de Kropotkin para Francisco Ferrer fica evidente a preocupação do geógrafo russo com os rumos da educação de então e externaliza, como bem vinda, a proposta de implantação de um ensino racionalista, característica fundamental da Escola Moderna catalã. Diz:

Tudo está por fazer na escola atual. Sobretudo a educação propriamente dita, isto é, formação do ser moral, ou seja, o indivíduo ativo, cheio de iniciativa, empreendedor, valente, livre dessa timidez do pensamento que caracteriza o homem educado em nossa época, e ao mesmo tempo sociável, igualitária, de instinto comunista, e capaz de sentir sua unidade com todos os homens do universo inteiro e, portanto, despojado das preocupações religiosas, estritamente individualistas, autoritárias, etc que nos inculca a escola. (KROPOTKIN, 2012, p.73)

A escola proposta por ele, de alguma forma, se remete às experiências que ocorriam na Escola Moderna: a formação de um aluno crítico, capaz de compreenderas mazelas sociais existentes e, principalmente, combater uma sociedade baseada na opressão de uma classe social sobre a outra.

Nesse projeto educacional, a Geografia escolar teria um grande papel a Geo UERJ. Rio de Janeiro - Ano 16, nº. 25, v.2, $2^{\circ}$ semestre de 2014, pp.231-249 
desempenhar: esclarecer aos alunos que as diferenças nacionais e a opressão dos povos dito "bárbaros" eram apenas traços de uma sociedade desigual e autoritária.

Nesse sentido, o geógrafo irá propor uma Geografia regida por princípios que valorizassem a solidariedade humana, o apoio mútuo em todas as esferas da vida (inclusive a econômica) e que o desenvolvimento do aluno estivesse ligado imbricamente à construção de uma identidade que superasse as implicações nacionais. Como o mesmo autor aponta:

Sem dúvida alguma, raramente pode existir outra ciência que possa tornar-se tão atrativa para a criança como a Geografia, um instrumento tão poderoso para o desenvolvimento geral da mente, para familiarizar o estudante com o autêntico método de raciocínio científico, e para despertar o gosto por todas as ciências naturais. (KROPOTKIN, 2012, p.36)

Embora soubesse que em pouquíssimas escolas o ensino de Geografia agradava e estimulava a capacidade cognitiva dos alunos, o geógrafo russo apontava a existência de algumas experiências, ainda que embrionárias, de escolas no qual o ensino geográfico diferenciava-se do que era comumente ministrado nas salas de aula daquela época.

Para ele, a Geografia escolar deveria contemplar 4 ramos do conhecimento científico:

1) Ser o estudo das leis a que estão submetidas as modificações da superfície terrestre.

2) Estudar as consequências da distribuição dos continentes e dos oceanos, das altitudes e depressões, das reentrâncias e das grandes massas de água sobre o clima.

3) Abordar a zoofitogeografia

4) Abordar as distintas famílias humanas existentes sobre a superfície da Terra.

No primeiro caso, a Geografia deveria ter como análise as morfoestruturas da Terra, revelando conceitos ainda poucos conhecidos acerca do surgimento da orografia continental, os aspectos morfoesculturais do relevo, demonstrando por uma série de estudos as variabilidades existentes nos continentes, mas também de que forma continentes distintos (caso da América e a Ásia) podem possuir cadeias montanhosas, nos quais a direção de soerguimento se repetem.

No segundo caso, Kropotkin propõe de que forma o conhecimento dos oceanos e dos continentes, ajuda a compreender a variabilidade climática mundial, tendo como 
ponto de análise a relação entre os mares e a distribuição das chuvas. Nesse caso, para ele caberia ao professor de Geografia, demonstrar que os fenômenos meteorológicos surgem pela intersecção de diversos fatorese na relação entre a dinâmica oceânica e as depressões e altitudes continentais.

No caso da zoofitogeografia, Kropotkin aponta a importância dos trabalhos de naturalistas do século XIX, casos de Darwin e Wallace, que possibilitaram superar a tendência descritiva então dominante. A partir dos estudos sobre a evolução das espécies e da formação do planeta, demonstrar por qual motivo os animais se distribuem pela Terra e a sua posterior evolução.

Por fim, cabe à Geografia escolar demonstrar aos alunos a existências dos vários grupos humanos, sua evolução, os aspectos culturais e sociais, bem como, a interrelação que esses atores sociais têm com a Natureza. Nesse caso, ao invés de "naturalizar" essa presença humana e reforçar a necessidade de um grupo humano em "civilizar" o outro, Kropotkin aponta a necessidade de se construir um amplo campo de conhecimento, que seja capaz de apontar essa grande diversidade.

Sabedor das dificuldades desse campo científico, Kropotkin analisa que a Geografia, por suas particularidades, deveria ter o papel de somar as várias experiências científicas existentes. Diz o geógrafo russo:

Nascerão muitas especialidades, algumas delas intimamente relacionadas coma história e com as outras ciências físicas; mas a autêntica obrigação da Geografia é a de cobrir de uma vez todo esse amplo campo e combinar em um quadro vivo todos os elementos separados desse conhecimento: representá-lo como um conjunto harmonioso, cujas partes são consequência de uns poucos princípios gerais e estão unidas entre si por suas mútuas relações. (KROPOTKIN, 2012, p.56)

Para Kropotkin, a Geografia escolar deveria então ter 3 grandes objetivos: despertar nas crianças a afeição pela ciência natural em seu conjunto; ensinar-lhes que todos os homens são irmãos, quaisquer que sejam as suas nacionalidades e, por fim, ensinar o respeito às chamadas "raças inferiores".

Para ele, caso a Geografia escolar não se preocupasse com esses pré-requisitos tornar-se-ia uma matéria pouco interessante aos alunos da educação básica.

Esse contato entre Kropotkin e Ferrer (fundador da Escola Moderna) propiciou que se buscasse, ao menos na educação libertária, outras formas de aprender e ensinar 
Geografia.

Um método que Kropotkin entendia como essencial para a compreensão das ciências naturais, mas também a Geografia, era o estudo do meio.

O estudo do meio possibilitaria uma outra compreensão existente entre os aspectos físicos e humanos, construídos na busca que o homem realiza constantemente para o domínio da natureza.

Esse método de ensino foi largamente usado nas escolas racionalistas que surgiam no país no início do século XX, contrapondo-se à uma educação geográfica pautada na memorização de estatísticas ou nomenclaturas.

Como demonstra Pontuschka (2009,p.176) a educação libertária existente no início do século XX compreendia que :

as escolas criadas pelos militantes do movimento anarquista tinham como princípio oferecer um ensino racional, fundamentado em observações de campo, em discussão e na formação do espírito crítico sobre o meio circundante, ou seja, o contexto social do entorno da escola ao qual pertenciam os alunos.

Kropotkin aponta o uso dessa metodologia de estudo em escolas, que mesmo não sendo libertárias, percebiam que o aprendizado tornaria-se agradável e consequentemente instigante, quando finalmente rompesse a barreira das salas de aula e fluisse pelo espaço à céu aberto.

Comentando sobre a importância do estudo do meio, Kropotkin (2009,p.62) analisa o sistema educacional desenvolvido na AgassizAssociation, associação escolar que possuía 7 mil alunos distribuídos em 600 seções:

As crianças dessa associação estão acostumadas a estudar as ciências naturais no campo, em meio à própria natureza.[...] Escrevem a outras sessões da Associação, trocam com elas suas observações, suas ideias, seus exemplares de minerais, plantas e animais. Escrevem sobre a paisagem do Canadá a amigos do Texas. Seus amigos suiços enviam edelweiss dos Alpes e os amigos ingleses explicam coisas sobre a geologia da Inglaterra.

Como aprender Geografia sem sair da sala de aula? Para o geógrafo anarquista isso era praticamente impossível. Somente por meio de trabalhos ao ar livre, estudando minerais, plantas mas também as inúmeras formas de ocupação humana, que o aluno se interessaria por essa ciência (e também pelas chamadas ciências naturais).

Geo UERJ. Rio de Janeiro - Ano 16, nº. 25, v.2, $2^{\circ}$ semestre de 2014, pp.231-249

ISSN: 1415-7543 E-ISSN: 1981-9021

http://www.e-publicacoes.uerj.br/index.php/geouerj 
Ainda que as distâncias entre as crianças fosse algo praticamente intransponível, o contato entre os alunos das várias seções da AgassizAssociation propiciava o conhecimento de regiões de vários países, possibilitando uma melhor compreensão da diversidade natural e humana do planeta.

Se a Geografia ainda hoje é vista com reticência por uma parte dos alunos dos ensino fundamental e médio, cabe a nós geógrafos descobrirmos outras técnicas de abordagem do conteúdo geográfico com o intuito de propiciar uma apreensão mais apurada da relação entre o homem e a natureza, muito ainda em várias escolas, analisadas separadamente.

Caso contrário, em pleno século XXI, momento marcado pela ampliação dos dispositivos tecnológicos, a Geografia ainda parecerá como algo menmônico, baseado em estatísticas frias, desinteressante para a maior parte dos alunos da educação básica.

\section{Considerações Finais}

Os estudos que discutem a pedagogia libertária e a sua influência na ciência geográfica ainda são extremamente escassos. Aqueles que demonstram a influência de pensadores anarquistas na estruturação dessa ciência e, nesse caso, a crítica ao modelo educacional existente, são praticamente desconhecidos.

Esse artigo procurou apontar como alguns autores anarquistas ou próximo dessa ideologia (caso de Lev Tolstoy) ao se depararem com a Geografia escolar do século XIX imprimiram uma crítica a ela, não se esquivando também de demonstrar também as potencialidades que essa disciplina escolar teria caso não fosse mnemônica ou excessivamente preocupada com nomenclaturas, a defesa do nacionalismo, entre outras propostas então dominantes.

Ao analisarmos a geografia escolar do século XIX pela crítica desses dois autores, procuramos demonstrar que, ainda que se tenha passado quase dois séculos, a Geografia escolar carece efetivamente de uma aplicação crítica a sua forma de explanação na escola.

Embora o movimento de renovação dessa disciplina seja da década de 1970, não é incomum ainda hoje a elaboração de propostas de ensino de geografia baseadas largamente na memorização de fatos, localização de países, etc.

Como vimos, Tolstoy e Kropotkin demonstravam profunda preocupação com a maneira que a Geografia era tratada nas escolas, buscando assim, apontar as 
potencialidades que a mesma poderia ter caso instigasse nos alunos a procura por novas relações entre o homem e a natureza, as diferenças culturais, ou mesmo, demonstrasse os fenômenos naturais que corriqueiramente perpassam as nossas vidas.

A Geografia, enquanto disciplina escolar, há muito tempo tem procurado se libertar de sua fase mnemônica, enciclopédica e tornar-se cada vez mais atrativa aos alunos do ensino básico, e por conseqüência, ter mais adeptos na universidade.

Esperamos que esse artigo possa, a partir das críticas empreendidas por Tolstoy e Kropotkin, contribuir para a formação de uma ciência mais dinâmica, ligada ao cotidiano discente sem se esquecer da sua relação com o mundo e, principalmente, forjar uma experiência educativa mais democrática, menos hierárquica e assim mais participativa.

\section{Referencias}

CODELLO, Francesco. A boa educação: experiências libertárias e teorias anarquistas na Europa, de Godwin a Neil. Volume 1. Tradução: Sile Cardoso. São Paulo: Editora Imaginário/Ícone, 2007.

FOUCAULT, Michel. Vigiar e punir. São Paulo: Editora Vozes, 2004.

GUARDIA, Francisco Ferrer Y. La escuela moderna. Barcelona: Ed. Solidariedad, 1912.

KROPOTKIN, Piotretall. Escritos sobre educação e geografia. Tradução: Rodrigo Rosa da Silva, Guilherme Amaral e Adriano Skoda. São Paulo: Biblioteca Terra Livre, 2009.

PAULA, Amir El Hakim de. Os operários pedem passagem! A geografia do operário na cidade de São Paulo (1900-1917). Dissertação de Mestrado. FFLCH-USP, 2005, $148 f$.

PONTUSCHKA, Nídia N. Estudo do meio: teoria e prática. Revista Geografia (Londrina), v.18, n.2, 2009.

TOLSTOY, Lev. La Escuela de YasnaiaPoliana. Madrid. Editora Jucar, 1978.

VESENTINI, José Willian. Controvérsias geográficas: epistemologia e política. Revista Confins, n.2, 2008.

Artigo recebido para publicação em março de 2014.

Artigo aceito para publicação em outubro de 2014.

Geo UERJ. Rio de Janeiro - Ano 16, nº. 25, v.2, $2^{\circ}$ semestre de 2014, pp.231-249

ISSN: 1415-7543 E-ISSN: 1981-9021

http://www.e-publicacoes.uerj.br/index.php/geouerj 